\title{
LAND USE/COVER CHANGE IN DINEVAR RURAL AREA OF WEST IRAN DURING 2000-2018 AND ITS PREDICTION FOR 2024 AND 2030
}

\author{
Mohammad MALEKII (D), John Lodewijk VAN GENDEREN ${ }^{\text {(D), }}$ \\ Seyed Mohammad TAVAKKOLI-SABOUR ${ }^{1}$, Samira Sadat SALEH ${ }^{1}$, Ehsan BABAEE
}

DOI : 10.21163/GT_2020.152.10

\begin{abstract}
:
Land use change, monitoring and predicting the future land use is often demanded by decision makers. Many land use change models have been developed aiming at the accurate prediction of land use changes. This study is aimed at mapping land use changes during past years and predicting the future trends in the rural environment of the Dinevar region to support local decision makers. For this research, we used the archive of Landsat satellite images of 2000, 2006, 2012 and 2018 to investigate the land-use changes in and initial pre-processes such as geometrical correction, radiometric correction. PCA was utilised to reduce the bands and multi-spectral images were fused with panchromatic band using Gram-Schmidt method to increase spatial separation. Four land uses of agriculture, rocky lands, pasture and bare soil were extracted through maximum likelihood method and predictions are made using CA-Markov chain. Land use for 2018 was predicted and the results were compared with the field observations, to evaluate the validity of the prediction method. Finally, the prediction was conducted for 2024 and 2030 land use. The highest extent of changes in the study period (2000-2030) was related to the change from pasture to bare soil with 1689 hectares. Based on the results, $0.7499 \%$ of changes were occurred between 2000 and 2006, 0.8562\% between 2000 and 2012, and remaining $15 \%$ from 2012 to 2018 . It indicates that the highest rate of changes in the area occurred within 20002006, while stagnation occurred in the period of 2006 to 2012. These changes increased during the last 5 -years due to the promotion of rural life. The results show that human activity and lifestyle changes have caused many changes in LULC in the area. Based on the results of this paper, many aspects of rural, agricultural, natural hazard, natural resources and even social studies can be understood in the study Reasons of land use changes are discussed at the end.
\end{abstract}

Key-words: Lands use, predicting the changes, Ca-Markov, Dinevar Rural area.

\section{INTRODUCTION}

Land use/cover (LULC) and its environmental effects have become the most debatable subject since 1990s and is considered as one of the major subjects of studying the global changes (Anderson et al.2017; Feddema et al., 2005; Luo et al, 2003; Liu, 1992; Wang et al, 2006). It has been figured out that the factors such as changing the land use and cutting the trees are very complicated (Golnow \& Lakes, 2014). "Land use/cover change detection can identify potential environmental events associated with rapid urbanisation, forest conversion, and agricultural expansion" (Zurqani et al., 2018; Drummond and Loveland, 2010; Agaton et al., 2016). The life in arid rural areas and limited natural resources cause poverty and may impact the overall living system of the people. The techniques of discovering changes using multi-temporal satellite imaging data helps to understand the dynamics of landscape such as desertification and land degradation which are considered as worldwide problems affecting soils, vegetation and the livelihoods of rural populations (Padonou et al., 2017; D'Odorico et al., 2013; Gao and Liu, 2010, Zhang et al.,2012). LULC are two different terms where, LC represents the physical characters of land surface such as spatial distribution of vegetation, water and other spatial features which are created merely by human residences (Dimyati et al, 1996). On the other hand, LU argues how the land is being exploited for human use and residence, e.g. the role of land for economic uses (Rawat \& Kumar, 2015). The changes of LU/LC

\footnotetext{
${ }^{1}$ Kharazmi University, Department of Remote Sensing \& GIS, Tehran-Iran, malekimohamad14@gmail.com, tavakkoli.khu.ac@yahoo.com, samiras.salehi1989@gmail.com,ehsanb86@gmail.com

${ }^{2}$ University of Twente, Department of Remote Sensing \& GIS, Netherlands, genderen@alumni.itc.nl
} 
are rapid and comprehensive procedures. Human activities in changing the land is absolutely significant through changing LULC (Liu et al, 2005; Tian et al, 2014; Liu and Tian, 2010; Hurtt et al, 2006; 2005b). Land cover data documents how much of a region is covered by forests, wetlands, impervious surfaces, agriculture, and other land and water types. Water types include wetlands or open water. Land use shows how people use the landscape - whether for development, conservation, or mixed uses. The different types of land cover can be managed or used quite differently (NOAA, 2019). Research studies aimed at integrating socio-economic and geo-bio-physical factors are increasingly being used in order to improve ourunderstanding of the causes and effects of land-use change and to support sustainable landscape development (Mottet et al, 2006). Identifying changes in land surface objects can provide valuable information for specialists in geometrics, crisis management, urban management, agriculture and forestry (Janalipour and Taleai, 2017).

Studies have shown that converting pastures to agricultural fields leads to the change in microbiological and biochemical properties of soil such as soil degradation etc. (Hajiabbasi et al, 2007; Aleagha et al, 2011). However, excessive exploitation of renewable natural resources (pastures) and the habitat supplying the needs of human population have had degrading effects on these important environmental resources. Such trend reduces the efficiency of these resources and threatens the human's life (Karimi and Karami Dehkordi, 2015; Hadeel, 2009). GIS provides a flexible environment for collecting, storing, displaying and analysing digital data necessary for change detection which has been used successfully in many developed and developing countries (Amade et al., 2018; Liping et al., 2018; Reis, 2008; Khan et al., 2016; Zeleke \& Hurni, 2001). Some studies have been conducted about seizing the land, changing the land use as well as converting the pastures to agriculture lands. (Wetzel, 2012; Wetzel, 2012; Hove \& Gwiza, 2015; Van der Sluis et al, 2017; You et al, 2015, Butt et al, 2009; Hajiabbasi et al, 2007; Aleagha et al, 2011 and Karimi and Karami Dehkordi, 2015). Keeping in mind the importance of land use and changes, the aim of this study is to investigate the extent of rural land use manipulation over the years 2000-2015430 using Remote Sensing Data and Geographic Information Systems (GIS) as well as its prediction for 2020 and 2025 years for Dinevar rural area in western Iran.

\subsection{Study Area}

Dinevar rural area is located in the central part of Dinevar section located in Kermanshah Province in the West of Iran. Dinevar Rural Area is located within geographical longitude of E4 $47^{\circ} 21^{\prime}$

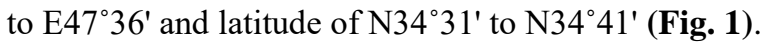

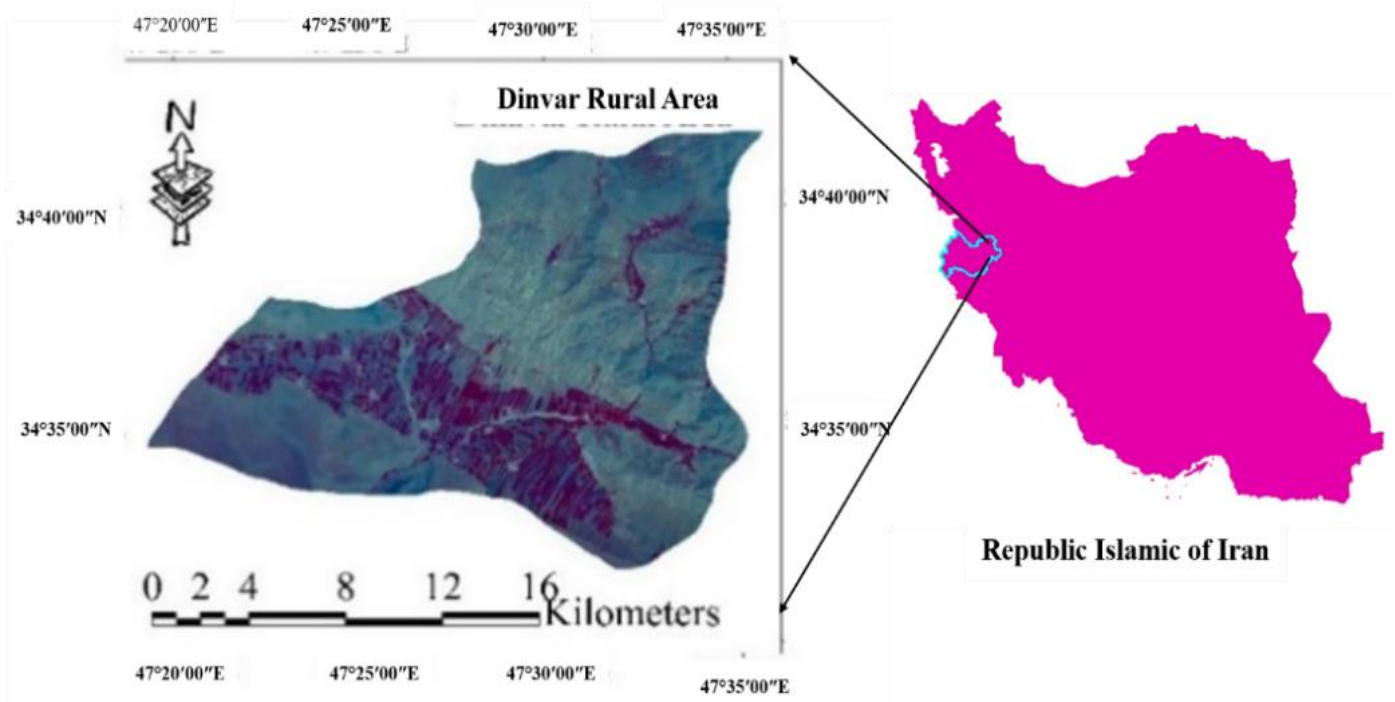

Fig. 1. The Location of Study Area in Iran. 
The extent of study area is 34,313 hectares. According to the statistics of 2013, this area contains 44 inhabited villages and 9201 residential population while major activities of the residents in this area include cultivation and pastoralism. Most of lands are cultivated as dry farming. The oldest settlement in the region dates back to $9800 \mathrm{BC}$ and is formed on a hill known as Sheikhi Abad near an adjacent river (Sadidi et al., 2016).

\section{METHODOLOGY}

\subsection{Data}

Landsat images of four time-points: 2000, 2006, 2012 and 2018 were used in this study. The goal is to detect the changes between four classes of land such as Agriculture, Pasture, bare Soil and Rocky Land. Considering the circumstances in the study area, the best time for imaging is late May to early June, since agricultural fields are still vegetated and not harvested at this period whereas pastures are almost dried out. Therefore, agricultural fields can be best separated from pastures and rocky lands during this time. Table 1 shows images used in this study. The images downloaded from archive of Earth-explorer site.

Table 1.

Images used.

\begin{tabular}{|c|c|c|c|}
\hline Resolution & $\begin{array}{c}\text { the exact } \\
\text { date }\end{array}$ & the path/row & $\begin{array}{c}\text { scene per } \\
\text { year }\end{array}$ \\
\hline $30 \mathrm{M}$ & 05-JUN-00 & Path: 167 / Row: 36 & 1 \\
\hline $30 \mathrm{M}$ & $06-\mathrm{JUN}-600$ & Path: 167 / Row: 36 & 1 \\
\hline $30 \mathrm{M}$ & 06-JUN-002 & Path: 167 / Row: 36 & 1 \\
\hline $30 \mathrm{M}$ & 15-JUN-008 & Path: 167 / Row: 36 & 1 \\
\hline
\end{tabular}

\subsection{Pre-processing and processing}

After providing the raw images, the primary pre-processing such as geometric and radiometric corrections were applied to prepare the images. Using Dark Object Subtraction, the atmospheric changes were applied on TM, ETM+ and OLI images. Principle Component Analysis (PCA) is one of the techniques that reduces the correlation on the cost of number of bands (Amini, 2009 and Rasouli, 2008). Therefore, PCA was used in this study to reduce the number of bands and to decorrelate the data. Multi-spectral images were fused to the single panchromatic band, in order to enhance spatial resolution using Gram-Schmidt technique (Jawak and Luis, 2013). The first components of a PCA contain the most information of the initial data. Fig. 2 shows an example of scree plot of eigenvalues vs. component number. The expected information is reduced with the component number which indicates an inverse correlation between component number and information content. The steep trend of the eigenvalues indicates the fast reduction of information with increasing component number. A threshold should be set in order to select the components containing the most information.

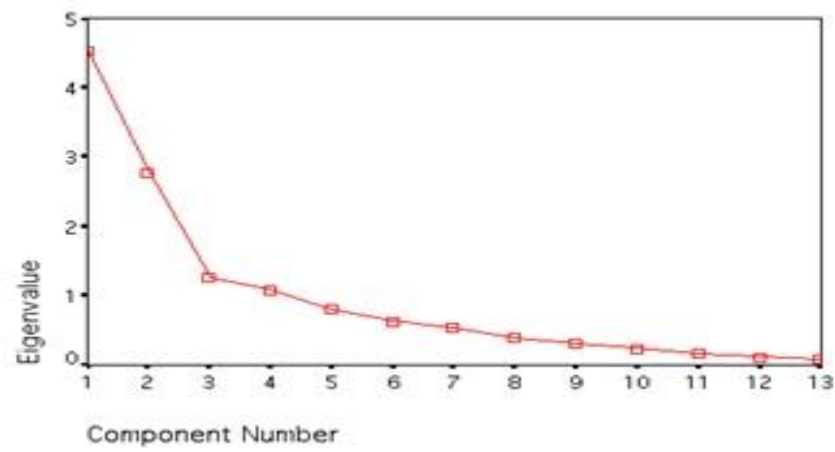

Fig. 2. Scree Plot. Eigenvalue vs. component number (janda.org, 2018). 


\subsection{Classification and predict changes}

Additional data sources like topography maps, field surveys, and google earth data were also used in this study. Strategy sampling using this classification, additional old data and images visual interpretation. The satellite images were classified by nearest neighbour classifier (Because usually a land use / cover is more than the area of a Landsat pixel method of sample collection was stratified random. Accuracy of results were evaluated based on error matrices and Kappa statistics. Finally, a map of LULC changes during 2000-2018 was provided. In order to predict the changes, CA-Markov technique was used. The changes were first predicted for 20188 in order to examine the reliability of techniques using available ground truth of 2015. The LULC predictions were made for years 2024 and 2030, then the user changes compared to year 2000 were identified. Markov models can be integrated with cellular automata models (a.k.a. Markov-CA models), and such models have been used to model and predict land use change at different scales (Guan et al., 2011; Weng, 2002; Ye \& Bai, 2008). The Markov-CA approach used in the current study is considered a spatial transition model as it combines the stochastic spatial Markov techniques with the stochastic spatial cellular automata method (Eastman, 2009). It has the advantage of predicting two-way transitions among the available LULC classes, in contrast to the Geomood technique that only predicts one-way loss/gain from one class to another (Pontius \& Malanson, 2005; Halmy et al, 2015). For the preparation of LULC maps used of ENVI software and for predict map use of Idrisi software. Table 2 shows size of reference samples for classification. Fig. 3 shows the flowchart of the methodology.

Table 2.

Size of reference samples.

\begin{tabular}{|c|c|c|c|c|c|}
\hline \multirow{4}{*}{ LULC } & \multicolumn{5}{|c|}{ Year } \\
\cline { 2 - 6 } & & $\mathbf{2 0 0 0}$ & $\mathbf{2 0 0 6}$ & $\mathbf{2 0 1 2}$ & $\mathbf{2 0 1 8}$ \\
\cline { 2 - 6 } & Agriculture & 1846 & 1546 & 2037 & 2565 \\
\cline { 2 - 6 } & Pasture & 569 & 723 & 719 & 547 \\
\cline { 2 - 6 } & bare Soil & 632 & 654 & 665 & 421 \\
\cline { 2 - 6 } & Rocky lands & 419 & 614 & 514 & 373 \\
\hline
\end{tabular}

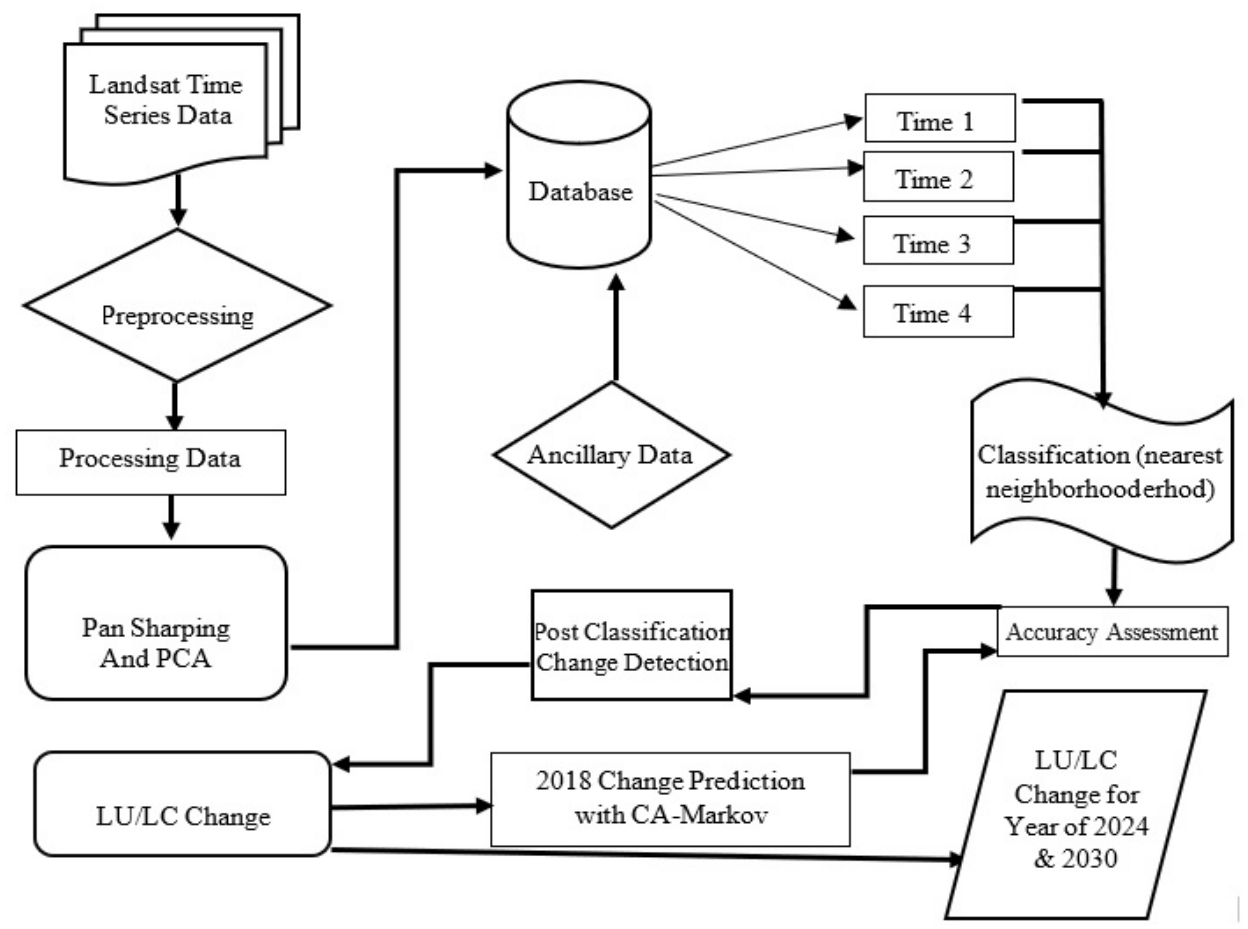

Fig. 3. The flowchart of methodology. 
Fig. 4 shows the PCA of TM and ETM+ data (right) and OLI (left). On the basis of the figure, it is clear that the longer we depart from the original component, give the less useful new information. This helps us to identify the principal components and extract the most information from the fewer number of image analysis. While Fig. 5 represents Scatter Plot of the images that facilitates the selection of features. Fig. 5 shows the correlation of image bands.
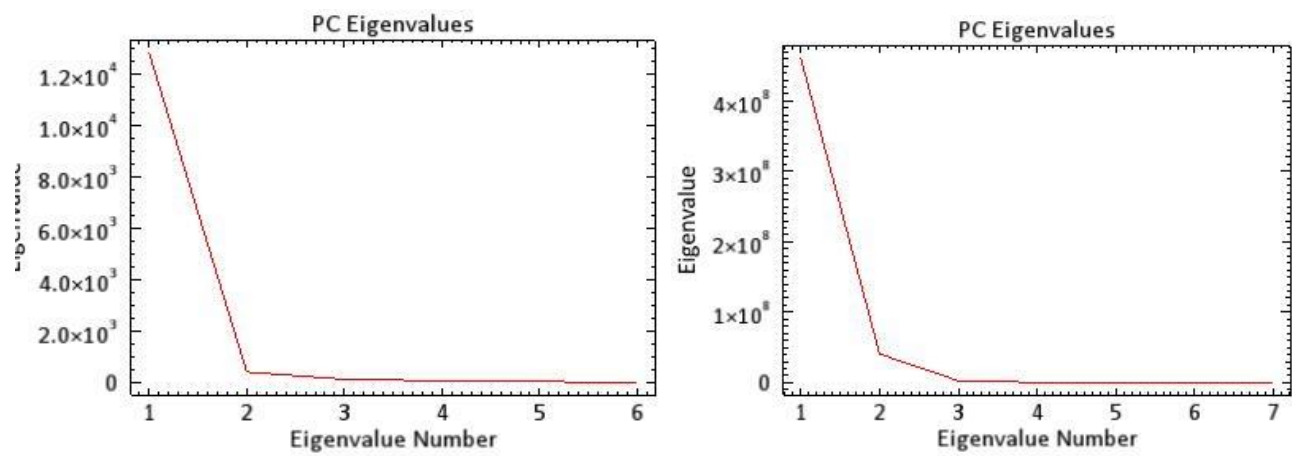

Fig. 4. Samples of Applying PCA on TM and ETM+ Data (left side) and OLI (right Side).
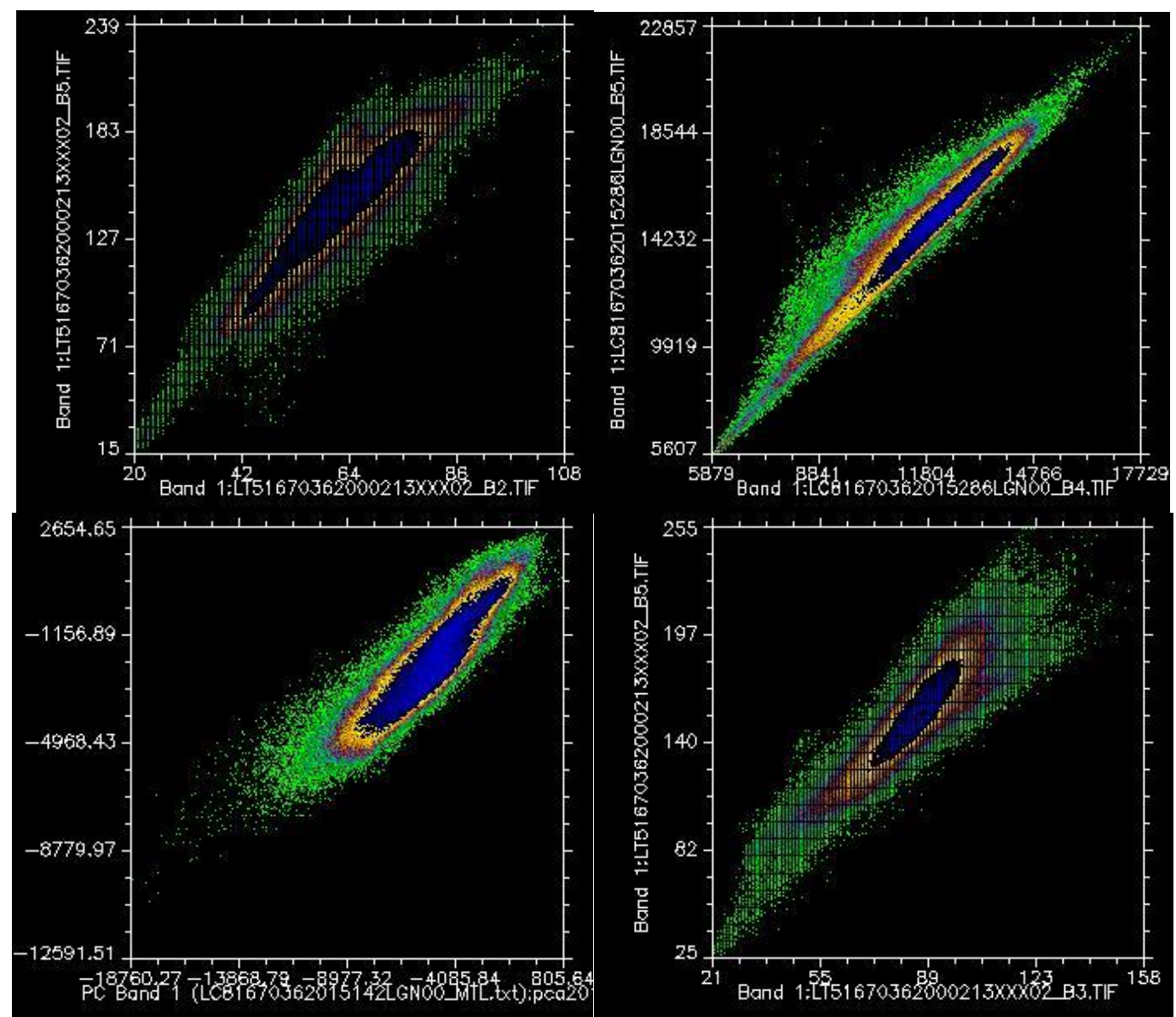

Fig. 5. Scatter Plot of Used Images in this Study. 


\section{RESULTS}

The statistical accuracy assessments of the classifications of produced maps are provided in Table 3. Based on the table, it is clear that a proper classification of LULC has been made in different periods.

Table 3.

The accuracy assessment of the produced maps.

\begin{tabular}{|c|c|c|c|c|}
\hline Years & Class & Completeness (\%) & Overall Accuracy & Kappa Coefficient \\
\hline \multirow{4}{*}{2000} & Agriculture & 94.37 & \multirow{4}{*}{89.55} & \multirow{4}{*}{81.31} \\
\hline & Pasture & 84.31 & & \\
\hline & bare Soil & 85.26 & & \\
\hline & Rocky lands & 94.26 & & \\
\hline \multirow{4}{*}{2006} & Agriculture & 93.73 & \multirow{4}{*}{89.50} & \multirow{4}{*}{81.30} \\
\hline & Pasture & 89.92 & & \\
\hline & bare Soil & 88.64 & & \\
\hline & Rocky lands & 85.69 & & \\
\hline \multirow{4}{*}{2012} & Agriculture & 90.33 & \multirow{4}{*}{90.15} & \multirow{4}{*}{86.07} \\
\hline & Pasture & 92.43 & & \\
\hline & bare Soil & 90.38 & & \\
\hline & Rocky lands & 87.47 & & \\
\hline \multirow{4}{*}{2018} & Agriculture & 91.61 & \multirow{4}{*}{87.7} & \multirow{4}{*}{81.09} \\
\hline & Pasture & 91.45 & & \\
\hline & bare Soil & 79.63 & & \\
\hline & Rocky lands & 88.12 & & \\
\hline
\end{tabular}

The resulted land use maps of 2000 and 2018 are respectively shown in Fig. 6 and Fig. 7. Using these maps, the changes in land use have been obtained for an 18 years period (The beginning and end of the course are the images in the study).

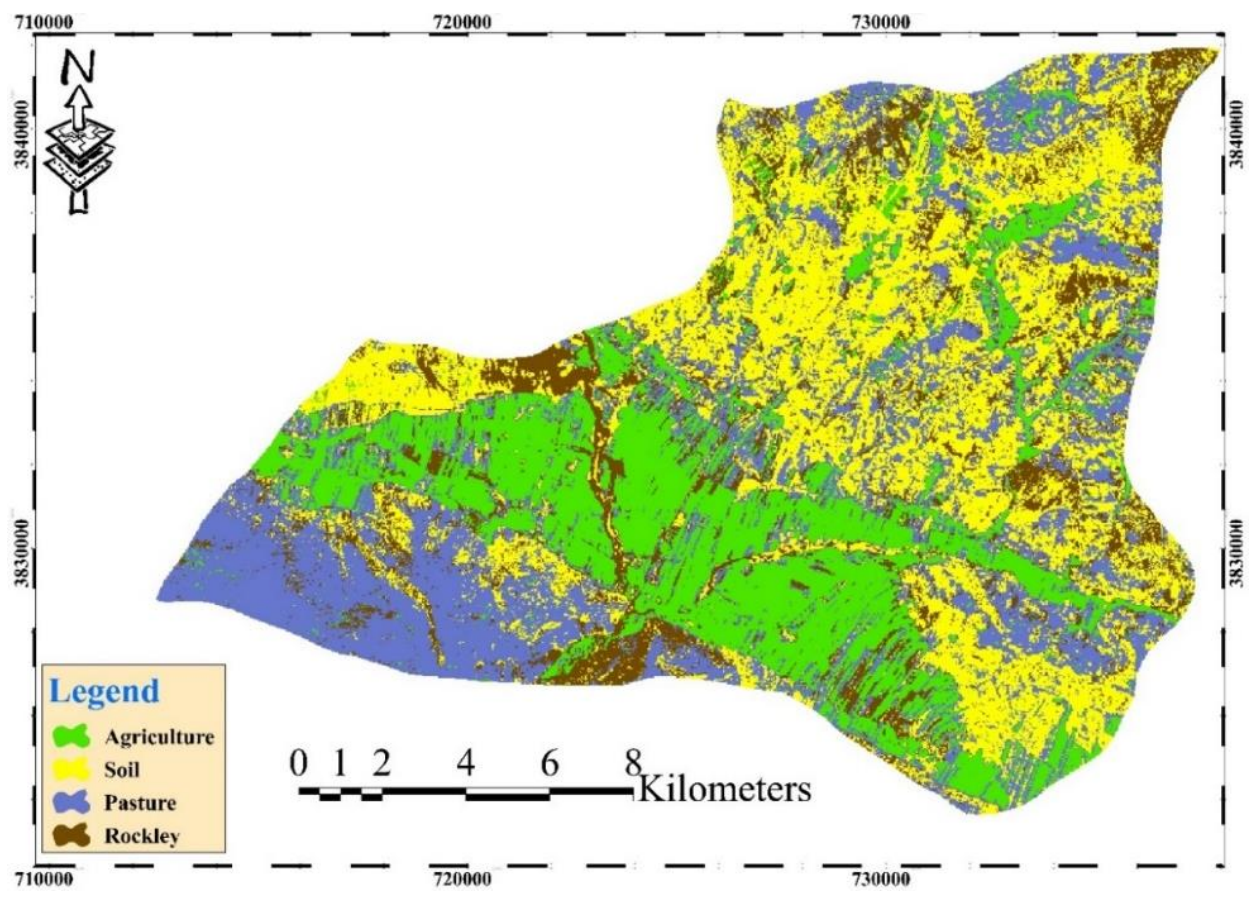

Fig. 6. Dinevar Land Use 2000. 


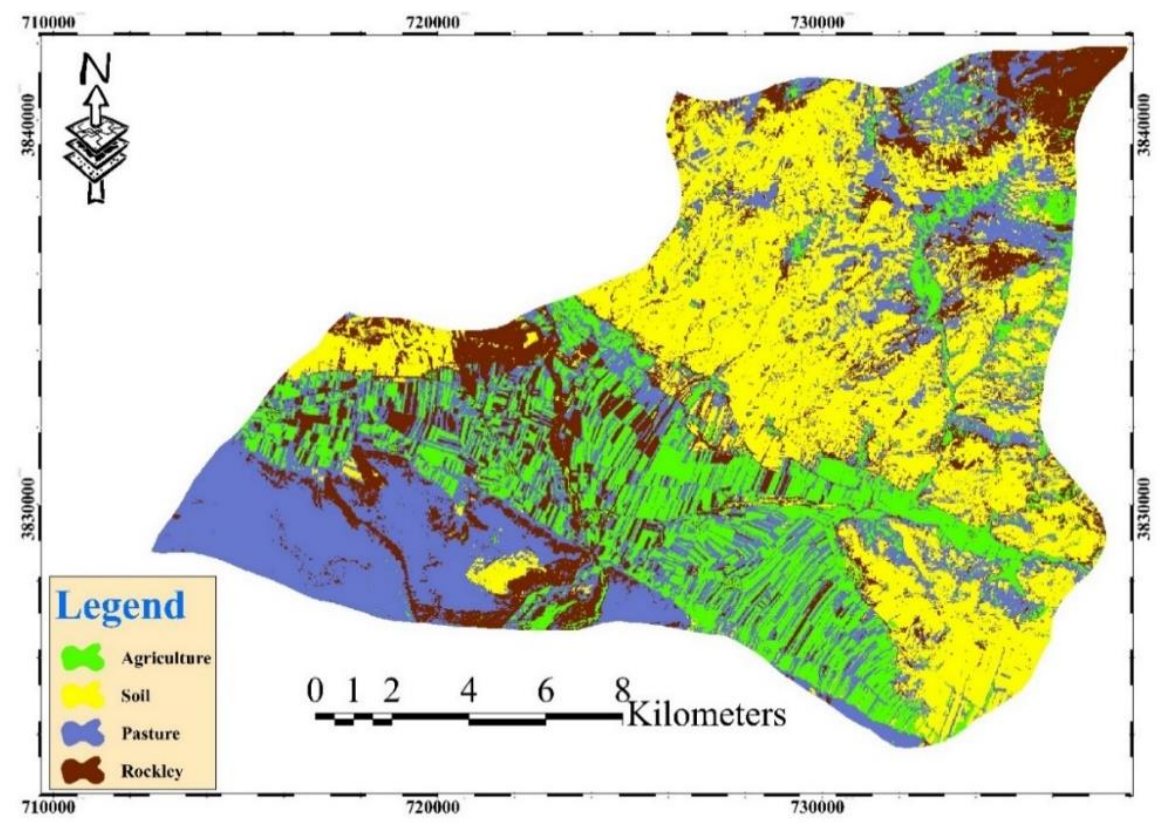

Fig. 7. Dinevar Land Use 2018.

The map of changes for 2018 compared to 2000 is represented in Fig. 8. 13 classes including no change and the changes of agriculture to the pasture, agriculture to bare soil, agriculture to rocky, pasture to agriculture, pasture to bare soil, pasture to rocky lands, bare soil to agriculture, bare soil to rocky lands, bare soil to pasture, rocky lands to agriculture, rocky lands to pasture and rocky lands to bare soil are shown in this map.

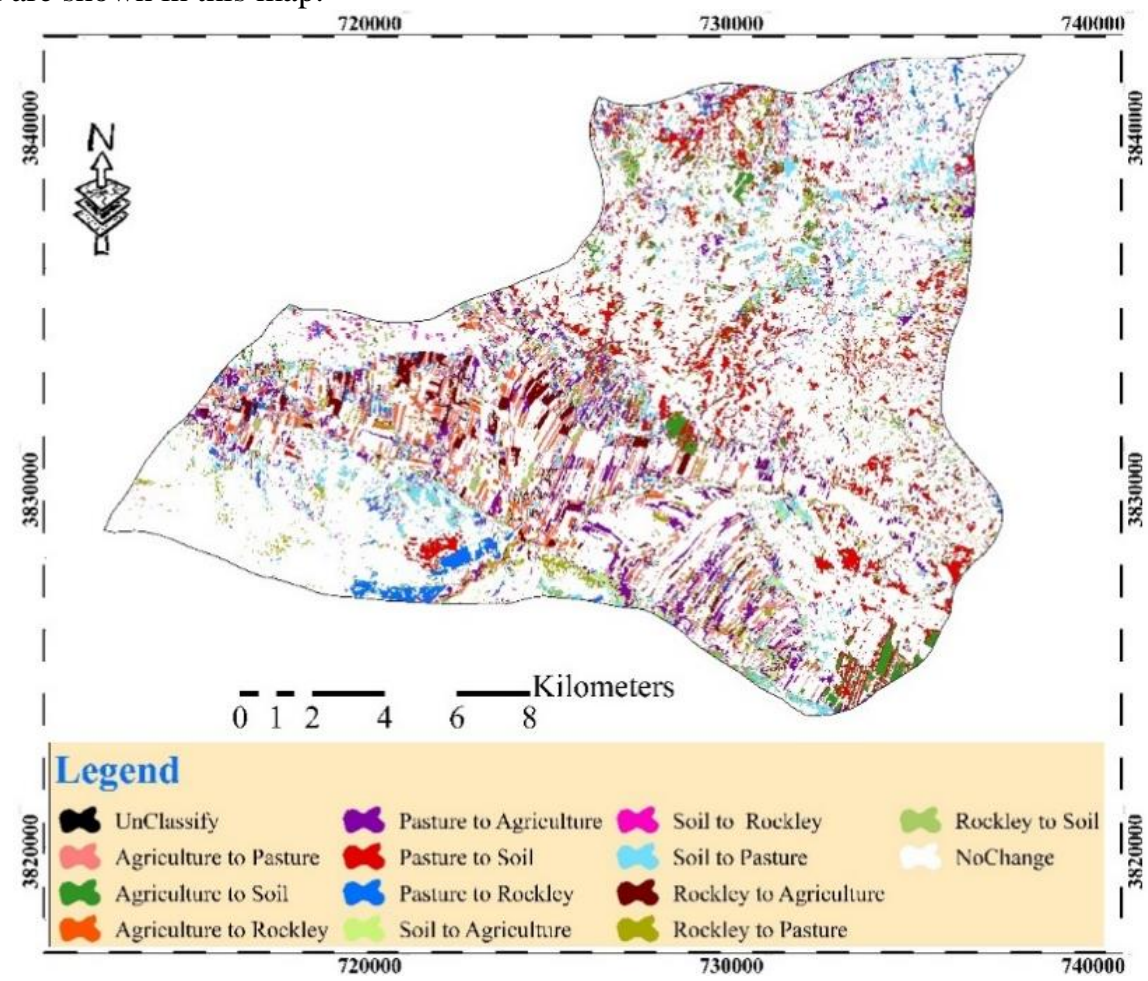

Fig. 8. Land Use Changes During 2000-2018. 
The predicted land use changes for 2018 using CA-Markov is provided as Fig. 9. Fig. 10 shows the prediction for 2024 based on the former trends. Also Fig. 11 shows LULC Changes for Year 2030, based on Year 2000 LULC Map.

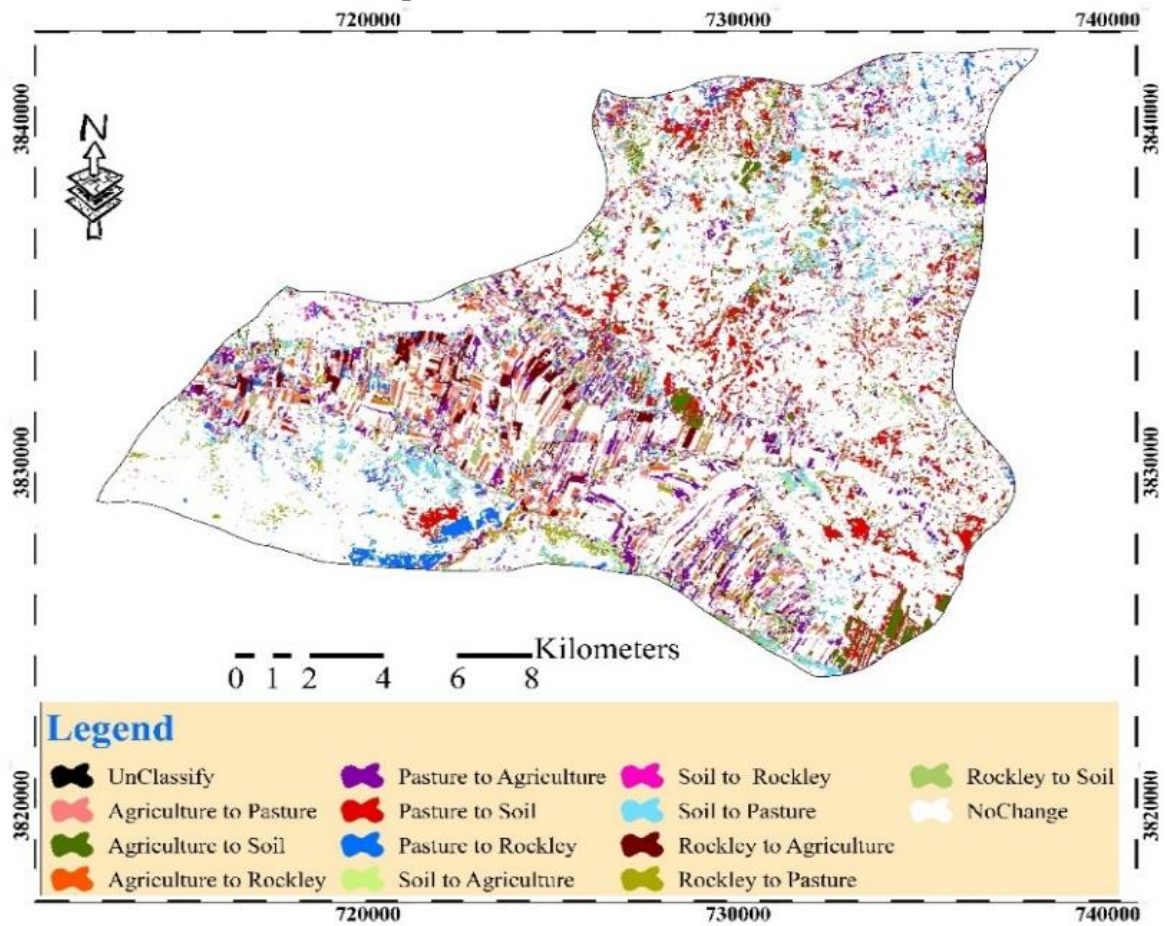

Fig. 9. Predicted Changes and Land Use Conversions During 2000-2018.

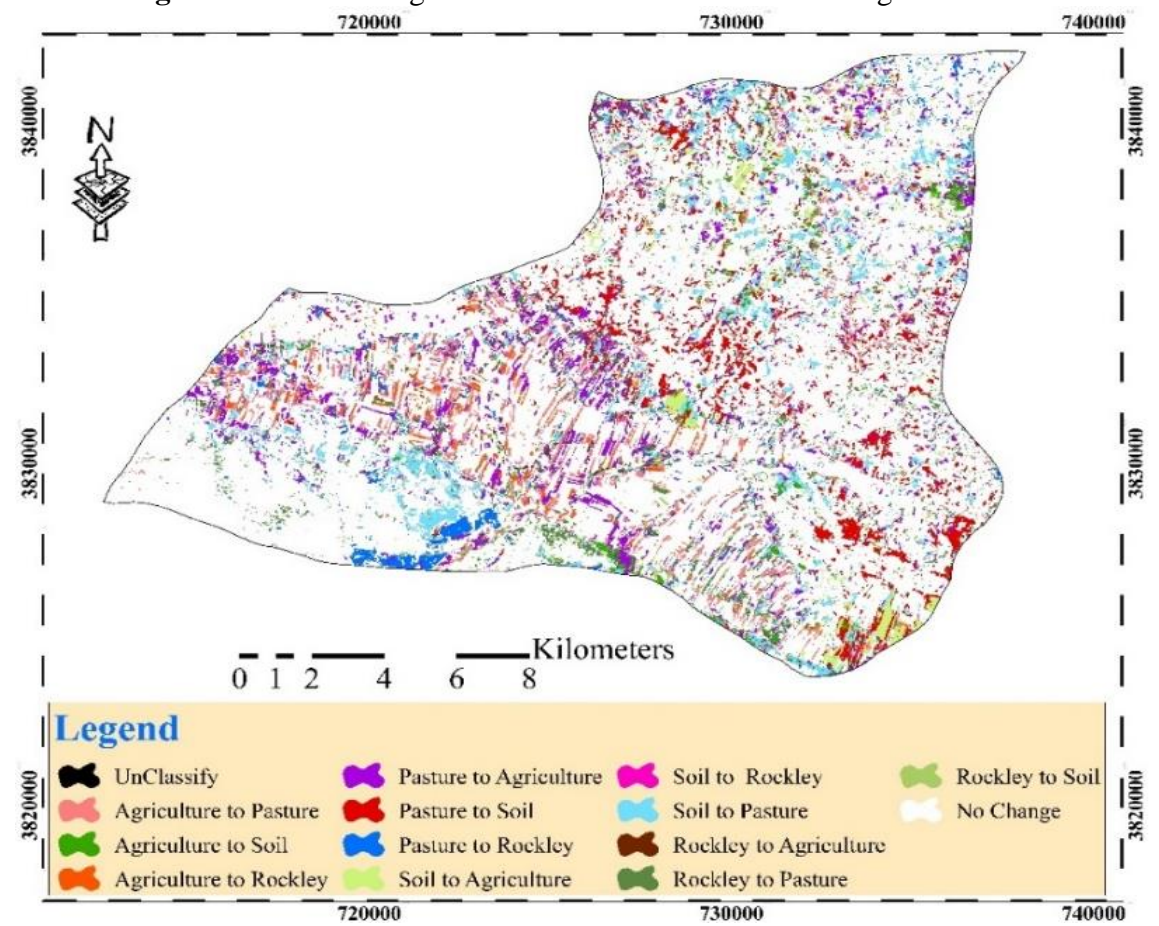

Fig. 10. Predicted Map of Land Use Changes During 2000-2024. 


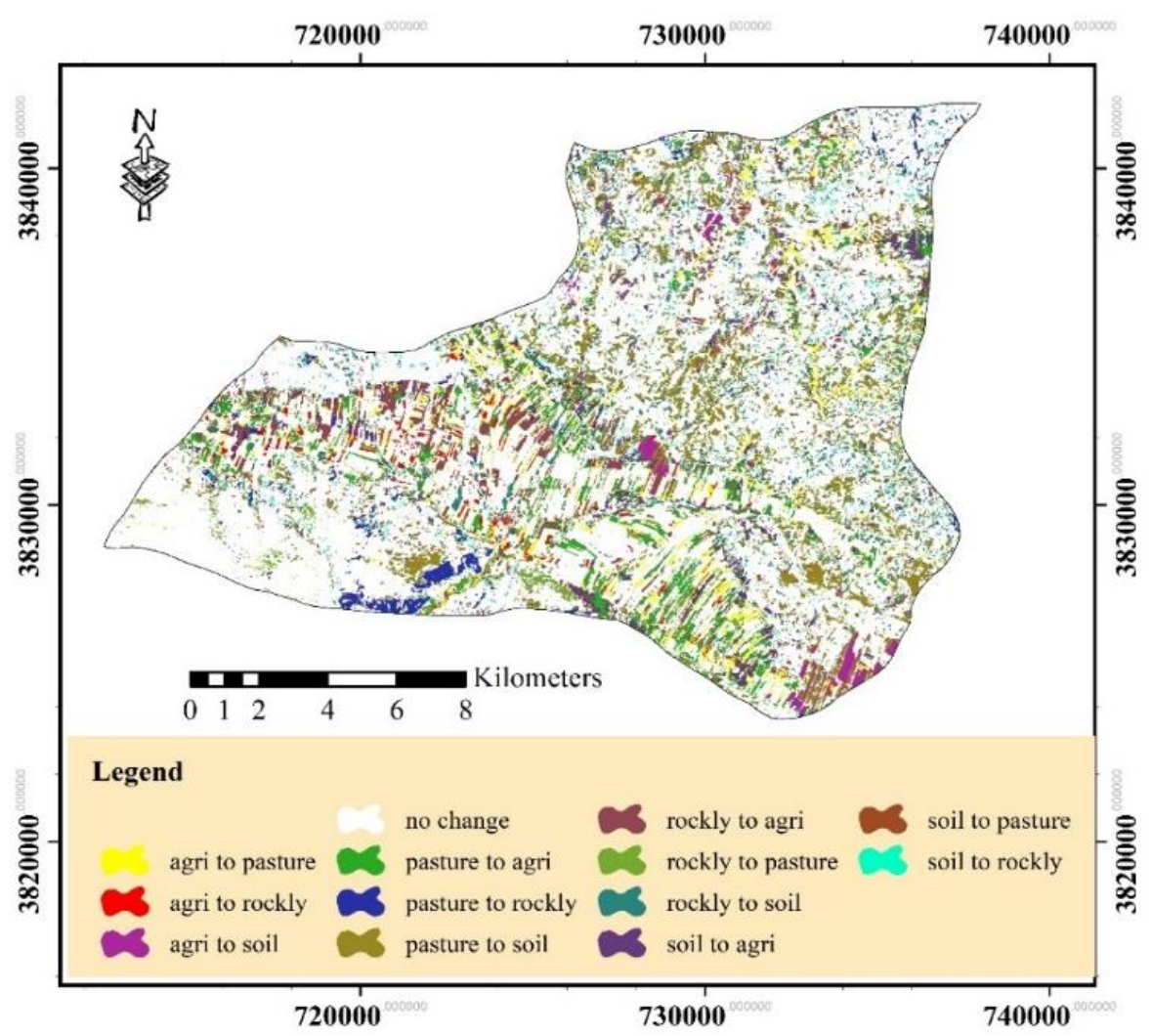

Fig. 11. Predicted Map of Land Use Changes During 2000-2030.

Fig. 12 shows the rate of land use changes during four periods; 2000-2006, 2000-2012, 20002018 and predicted 2000-2024 and 2000-2030. The rate of converting agriculture to bare soil, pasture to rocky and rocky to pasture during 2000-2024 will be less in comparison with 2000-2018.

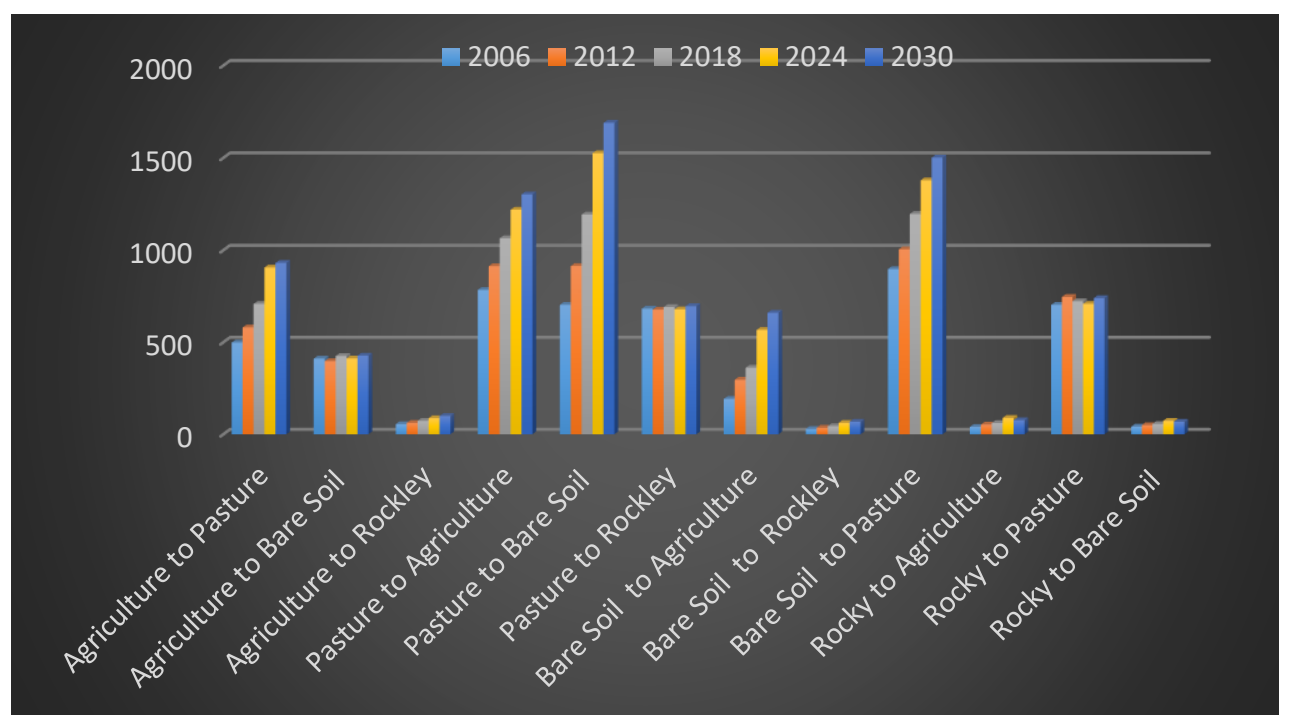

Fig. 12. Extent of land use changes in different periods (hectares). 


\section{DISCUSSION}

It should be considered that it is impossible to achieve $100 \%$ accuracy in the results and the results might include an error rate. One of the main sources of error is the annual period of selection. In addition, it is not always possible to provide satellite data at the same date in all selected years. Hamed et. al investigated land use change predictions under two different conditions (sanctioned or not sanctioned) in the Iraq's Kurdistan and concluded that the environment will be led to stability and homogeneity, if the region is not sanctioned during the next 6 years. Halmy et. al (2015) showed that land use changes and urbanization will extend mainly towards the west and north.

Results showed that a high classification accuracy could be achieved via CA-Markov which can predict changes in 2018. Moreover, the evaluation of land use in 2024 was not possible which might also create a minimal error in maps. Most obvious trend of the changes is the conversion of pasture to farmlands and degradation to bare land. Land use change has become a fundamental factor in environmental change and has become a global threat. Reviewing these changes through satellite imagery and predicting these changes can help planners. According to the results of this paper, the trend of degradation and change in environment and LULC between years 2000 to 2006 is greater than any other period. The highest gradient of change was for changing pasture land cover to soil bare, indicating the destruction of rangelands. On the other hand, the second gradient of change was related to the conversion of bare soil to grassland, which indicates the restoration of rangelands in some places.

\section{CONCLUSION}

According to Alimohammadi et al (2010), Markov chain has great capability to predict land use changes. They found that the change from agriculture to settlement has been the most observed changes and this trend is going to continue in the future. Prediction of changes is often conducted aiming at evaluation of land use change consequences (Alimohammadi et. al 2010), whereas the most studies have been unconcerned about the cause of changes. This study is concerned not only about the usual issues of other studies, but also about the causes of land use changes, which may help the decision makers to prevent the disadvantages of changes.

Following change reasons have been identified in this research with respect to each type of land use change:

- Pasture to agriculture: it happens due to the demand of profit and food production. Some fallow fields may be classified as pasture and are considered as a change from pasture to agriculture or vice versa (for example in the image of 2000, it has been shown as pasture and in other periods they were turned to agricultural land)

- Pasture to bare Soil: due to high density of livestock and excessive exploitation of pasture, especially near water sources and around villages.

- Pasture to Rockley land: excessive exploitation of rocky pastures and shortage in water supply.

- Agriculture to pasture: stopping the cultivation and leaving fields unused due to infertility, water shortage or immigration of the owners (sometimes evacuating the residences) or fallowing the fields allowing pasture plants to grow.

- Agriculture to bare Soil: fallowing the land through cultivation of some products like peas. In this case, more than a half of land is exposed as bare soil and the product grows sparsely which may cause a misclassification as bare soil.

- Agriculture to Rocky land: soil degradation and erosion may force farmers to leave rocky fields and stop the cultivation.

- Bare Soil to agriculture: planting the lands which were fallow previously or planting very weak or those pastures which were not cultivated previously.

- bare Soil to pasture: growing pasture plants in the lands with bare soil cover where less amount of livestock is present 
- Bare Soil to Rocky land: this might be because of erosion or exploitation and brick factories in the region which have reached to the beneath layers by soil extraction.

- Rocky land to agriculture: cultivating rocky lands which is common in mountainous and poor villages

- Rocky land to pasture: low exploitation of mountain lands, due to the reduction in number of people working as traditional animal farmers which bare lead mountains to recover the vegetation and regenerate the pastures.

- $\quad$ Rocky land to bare Soil: there is some sand factories in the selected region, in which rocky lands can be converted to bare soil as a result of covering rocks with deposited bare soil.

\section{R E F E R E N C E S}

Agaton, M., Setiawan, Y. and Effendi, H., 2016. Land use/land cover change detection in an urban watershed: a case study of upper Citarum Watershed, West Java Province, Indonesia. Procedia Environmental Sciences, 33, pp.654-660.

Alimohammadi, Abbas, Mousivand, Alijafar and Shayegan, siavash., 2010. Predicting the LU/LC changes of land surface using satellite images and Markov chain, planning and space alignment, period 14, number 3 , pp. 117-130. (In Farsi).

Amade, N., Painho, M. and Oliveira, T., 2018. Geographic information technology usage in developing countries-A case study in Mozambique. Geo-spatial Information Science, 21(4), pp.331-345.

Amini, Jalal (2009). Computer processing of remote assessment images (translated by: M. Mizer), Tehran University publication, Tehran, Iran, P650. (In Farsi).

Anderson, K., Ryan, B., Sonntag, W., Kavvada, A. and Friedl, L., 2017. Earth observation in service of the 2030 Agenda for Sustainable Development. Geo-spatial Information Science, 20(2), pp.77-96.

Beheshti-aleagha, Ali; Raeisi, Faez; and Golchin, Ahmad., 2011. The effect of land use changes from pasture to farm on the microbiological and biochemical indicators of soil, the journal of water and soil, vol. 25, number 3, pp 548-562. In Farsi.

Butt, A., Shabbir, R., Ahmad, S.S. and Aziz, N., 2015. Land use change mapping and analysis using Remote Sensing and GIS: A case study of Simly watershed, Islamabad, Pakistan. The Egyptian Journal of Remote Sensing and Space Science, 18(2), pp.251-259.

D’Odorico, P., Bhattachan, A., Davis, K.F., Ravi, S. and Runyan, C.W., 2013. Global desertification: drivers and feedbacks. Advances in water resources, 51, pp.326-344.

Dimyati, M.U.H., Mizuno, K., Kobayashi, S. and Kitamura, T., 1996. An analysis of land use/cover change in Indonesia. International Journal of Remote Sensing, 17(5), pp.931-944.

Drummond, M.A. and Loveland, T.R., 2010. Land-use pressure and a transition to forest-cover loss in the eastern United States. BioScience, 60(4), pp.286-298.

Eastman, J.R., 2009. IDRISI guide to GIS and image processing Accessed in IDRISI Selva 17 (pp. 182e185). Worcester, MA: Clark University.

Falcucci, A., Maiorano, L. and Boitani, L., 2007. Changes in land-use/land-cover patterns in Italy and their implications for biodiversity conservation. Landscape ecology, 22(4), pp.617-631.

Fang, S., Yan, J., Che, M., Zhu, Y., Liu, Z., Pei, H., Zhang, H., Xu, G. and Lin, X., 2013. Climate change and the ecological responses in Xinjiang, China: Model simulations and data analyses. Quaternary International, 311, pp.108-116.

Fatemi, Sayyed-Bagher., Rezaei, Yosef., 2012. Principles of Remote Sensing. Azadeh Publishing. Pp 296. (In Farsi).

Feddema, J.J., Oleson, K.W., Bonan, G.B., Mearns, L.O., Buja, L.E., Meehl, G.A. and Washington, W.M., 2005. The importance of land-cover change in simulating future climates. Science, 310(5754), pp.1674-1678.

Gao, J. and Liu, Y., 2010. Determination of land degradation causes in Tongyu County, Northeast China via land cover change detection. International Journal of Applied Earth Observation and Geoinformation, 12(1), pp.9-16.

Gollnow, F. and Lakes, T., 2014. Policy change, land use, and agriculture: The case of soy production and cattle ranching in Brazil, 2001-2012. Applied Geography, 55, pp.203-211. 
Guan, D., Li, H., Inohae, T., Su, W., Nagaie, T. and Hokao, K., 2011. Modeling urban land use change by the integration of cellular automaton and Markov model. Ecological Modelling, 222(20-22), pp.3761-3772.

Hadeel, A., Jabbar, M. and Chen, X., 2009. Application of remote sensing and GIS to the study of land use/cover change and urbanization expansion in Basrah province, southern Iraq. Geo-spatial Information Science, 12(2), pp.135-141.

Hajiabbasi, Mohammadali, Besharatpour, Asghar and Melali, Ahmadreza., 2007. The effect of converting the pastures to agriculture lands on physical and chemical characteristics of soils of south and southwest of Isfahan, agricultural sciences and techniques, number 42, pp 525-534 (In Farsi).

Halmy, M.W.A., Gessler, P.E., Hicke, J.A. and Salem, B.B., 2015. Land use/land cover change detection and prediction in the north-western coastal desert of Egypt using Markov-CA. Applied Geography, 63, pp.101112.

Hamad, R., Balzter, H. and Kolo, K., 2018. Predicting land use/land cover changes using a CA-Markov model under two different scenarios. Sustainability, 10(10), p.3421.

Hove, M. and Gwiza, A., 2012. The fast track land reform programme and food insecurity: A case of Zimbabwe from 1992 to the present. American International Journal of Contemporary Research, 2(8), pp.282-293.

Hurtt, G.C., Frolking, S., Fearon, M.G., Moore, B., Shevliakova, E., Malyshev, S., Pacala, S.W. and Houghton, R.A., 2006. The underpinnings of land-use history: Three centuries of global gridded land-use transitions, wood-harvest activity, and resulting secondary lands. Global Change Biology, 12(7), pp.1208-1229.

Janalipour, M. and Taleai, M., 2017. Building change detection after earthquake using multi-criteria decision analysis based on extracted information from high spatial resolution satellite images. International journal of remote sensing, 38(1), pp.82-99.

Jawak, S.D. and Luis, A.J., 2013. A comprehensive evaluation of PAN-sharpening algorithms coupled with resampling methods for image synthesis of very high resolution remotely sensed satellite data. Advances in Remote Sensing, 2, pp.332-344

Karimi, Kobra; Karami Dehkordi, Esmaeil., 2015. Exploiting the pastures and the necessity of diversifying the livelihood of rural families, case study: MAhanshan Town, rural research, period 6, number 2. PP 342-368 (In Farsi).

Kaveh, Neda; Ebrahimi Atalloh., 2013. Predicting the LU/LC changes through CA-Markov model (case study: Aghbolagh river). Remote assessment and the system of geographical information in natural resources, period 2, number 4: pp 41-51(In Farsi).

Khan, S., Qasim, S. and Ambreen, R., 2016. Spatio-temporal analysis of landuse/landcover change of district pishin using satellite imagery and GIS. Journal of Geographic Information System, 8(3), pp.361-368.

Liping, C., Yujun, S. and Saeed, S., 2018. Monitoring and predicting land use and land cover changes using remote sensing and GIS techniques-A case study of a hilly area, Jiangle, China. PloS one, 13(7).

Liu, J., Liu, M., Tian, H., Zhuang, D., Zhang, Z., Zhang, W., Tang, X. and Deng, X., 2005a. Spatial and temporal patterns of China's cropland during 1990-2000: an analysis based on Landsat TM data. Remote sensing of Environment, 98(4), pp.442-456.

Liu, J., Tian, H., Liu, M., Zhuang, D., Melillo, J.M. and Zhang, Z., 2005b. China's changing landscape during the 1990s: Large-scale land transformations estimated with satellite data. Geophysical Research Letters, 32(2).

Liu, M. and Tian, H., 2010. China's land cover and land use change from 1700 to 2005: Estimations from highresolution satellite data and historical archives. Global Biogeochemical Cycles, 24(3).

Luo, G., Zhou, C. and Chen, X., 2003. Process of land use/land cover change in the oasis of arid region. ACTA GEOGRAPHICA SINICA-CHINESE EDITION-, 58(1), pp.63-72.

Mottet, Anne, Sylvie Ladet, Nathalie Coqué, and Annick Gibon. "Agricultural land-use change and its drivers in mountain landscapes: A case study in the Pyrenees." Agriculture, ecosystems \& environment 114, no. 2-4 (2006): 296-310.

Padonou, E.A., Lykke, A.M., Bachmann, Y., Idohou, R. and Sinsin, B., 2017. Mapping changes in land use/land cover and prediction of future extension of bowé in Benin, West Africa. Land Use Policy, 69, pp.85-92.

Pontius, G.R. and Malanson, J., 2005. Comparison of the structure and accuracy of two land change models. International Journal of Geographical Information Science, 19(2), pp.243-265.

Rasouli, Aliakbar., 2008. The principles of applied remote assessment emphasizing on the process of satellite images, Tabriz University Publication, Tabriz, Iran, p806. (In Farsi). 
Rawat, J.S. and Kumar, M., 2015. Monitoring land use/cover change using remote sensing and GIS techniques: a case study of Hawalbagh block, district Almora, Uttarakhand, India. Egypt J Remote Sens Space Sci 18 (1): 77-84.

Reis, S., 2008. Analyzing land use/land cover changes using remote sensing and GIS in Rize, North-East Turkey. Sensors, 8(10), pp.6188-6202.

Sadidi, J., Maleki, M., Rahmati, M. and TAVAKKOLI, S.M., 2016. Investigating the Role of Faults in the Establishment and Survival of Settlements using Remote Sensing and Geographic Information System (GIS). The Case of Sahneh County in Iran. Journal of Settlements and Spatial Planning, 7(2), pp.201-206.

Song, X.P., Huang, C. and Townshend, J.R., 2017. Improving global land cover characterization through data fusion. Geo-spatial information science, 20(2), pp.141-150.

Tian, H., Banger, K., Bo, T. and Dadhwal, V.K., 2014. History of land use in India during 1880-2010: Largescale land transformations reconstructed from satellite data and historical archives. Global and Planetary Change, 121, pp.78-88.

Tracewski, L., Bastin, L. and Fonte, C.C., 2017. Repurposing a deep learning network to filter and classify volunteered photographs for land cover and land use characterization. Geo-spatial information science, 20(3), pp.252-268.

van der Sluis, T., Pedroli, B., Kristensen, S.B., Cosor, G.L. and Pavlis, E., 2016. Changing land use intensity in Europe-Recent processes in selected case studies. Land Use Policy, 57, pp.777-785.

Wang, X.Z., Zheng, Y.H. and Li, S., 2006. Analysis of land use and landscape pattern change in west of Hainan Island. Journal of Desert Research, 26(3), pp.409-414.

Wang, Y., Chen, Y., Ding, J. and Fang, G., 2015. Land-use conversion and its attribution in the Kaidu-Kongqi River Basin, China. Quaternary international, 380, pp.216-223.

Weng, Q., 2002. Land use change analysis in the Zhujiang Delta of China using satellite remote sensing, GIS and stochastic modelling. Journal of environmental management, 64(3), pp.273-284.

Wetzel, C., 2009. Theorizing Native American land seizure: An analysis of tactical changes in the late twentieth century. Social Movement Studies, 8(1), pp.17-34.

Wetzel, C., 2012. Envisioning land seizure: Diachronic representations of the occupation of Alcatraz Island. American Behavioral Scientist, 56(2), pp.151-171.

Ye, B., \& Bai, Z., 2008. Simulating land use/cover changes of Nenjiang County based on CA-Markov model. International Federation for Information Processing PublicationsIFIP, 258, $321 \mathrm{e} 330$.

You, W., Ji, Z., Wu, L., Deng, X., Huang, D., Chen, B. and He, D., 2017. Modeling changes in land use patterns and ecosystem services to explore a potential solution for meeting the management needs of a heritage site at the landscape level. Ecological Indicators, 73, pp.68-78.

Zeleke, G. and Hurni, H., 2001. Implications of land use and land cover dynamics for mountain resource degradation in the Northwestern Ethiopian highlands. Mountain research and development, 21(2), pp.184191.

Zhang, F., Tashpolat, T., Kung, H.T. and Ding, J., 2010. The change of land use/cover and characteristics of landscape pattern in arid areas oasis: an application in Jinghe, Xinjiang. Geo-spatial Information Science, 13(3), pp.174-185.

Zhao, W., Yan, L. and Zhang, Y., 2018. Geometric-constrained multi-view image matching method based on semi-global optimization. Geo-spatial information science, 21(2), pp.115-126.

Zurqani, H.A., Post, C.J., Mikhailova, E.A., Schlautman, M.A. and Sharp, J.L., 2018. Geospatial analysis of land use change in the Savannah River Basin using Google Earth Engine. International journal of applied earth observation and geoinformation, 69, pp.175-185.

http://www.janda.org/workshop/factor\%20analysis/SPSS\%20run/SPSS08.htm accessed on 23.12.2018

https://oceanservice.noaa.gov/facts/lclu.html acsses on 13.10.2019. 